\title{
OTRO LECTOR DE GÓNGORA DISCONFORME CON SALCEDO
}

No hace mucho tiempo apareció en las páginas de esta revista un interesante artículo de Edward M. Wilson, La estếtica de Don García Salcedo Coronel y la poesía española del siglo Xvir ${ }^{1}$. En él nos da cuenta de las curiosas, y casi siempre acertadas, notas manuscritas que un tal Pedro Soriano Carranza puso a un ejemplar de las Soledades gongorinas comentadas por Salcedo ${ }^{2}$. Estas apostillas son una defensa de la obra de don Luis en casos en que el comentador censura algún pasaje. Don García se atrevió a poner ciertos reparos - la verdad es que muy leves y de tarde en tarde- al cordobés, y en un monxento de tal gongolatría, como Wilson dice, muy pocos soportaban la más pequeña crítica a las Soledades. Así hasta los simples lectores, en sus propios ejemplares, y, por decirlo así, en secreto, se apresuraban a jurar las poéticas palabras de Góngora.

En diez ocasiones apostilló Soriano su volumen, propiedad hoy de Wilson. A éstas añado ahora trece notas que un lector anónimo puso al ejemplar conservado en Madrid, en la Biblioteca del Instituto Miguel de Cervantes del Consejo Superior de Invesaigaciones Científicas (signatura: XVII/98). Al final las comento muy sucintamente, pues no tienen el interés - contienen, incluso, graves errores-- de las presentadas por Wilson, aunque creo pueden unirse a ellas como ilustración de una fama y de una dictadura poética: la de Góngora y sus apasionados. Es curioso señalar que ambos anotadores, el desconocido y el anónimo, coinciden en sus iras contra Salcedo en una de las notas: la 2 de Soriano, 5 del anónimo ${ }^{3}$.

\section{XLIV, págs. 1-27.}

solcdudes de 1). Luis de Góngora. Comentadas por D. García de Salzedo Coronel. En Madrid ,en la Imprenta Real, 1636.

3 Para editar las notas sigo el mismo orden de Wilson: verso que motiva el comentario, citado por la edición de DÁmso Alorso. (Madrid 3." edición. Sociedad de cstudios y publicaciones. 1956), palabras de Salcedo y nota manuscrita anónima. 
1. ...piadoso miembro roto / -breve tabla-... (I, 17-18).

Salcedo: Finge don Luis, a lo que presumo, este naufragio en las costas de Italia (folio 19r.)

nota anónima: engañase este autor porque en ambas Soledades consta que Góngora puso este naufragio en el mar océano, vide infra fol. $271 z^{\prime}$ y fol. 295 (4).

2. ...indigna tiara / - si tradición apócrifa no miente- / de animal tenebroso. (I, 73-75). Salcedo: Dexóse lleuar don Luis del error pueril de los que dizen que el Carbunco lo trae cierto animal en la cabeça, y que de noche respla[n]dece como llama de fuego, sin que hasta oy ayamos visto este animal.

nota anónima: este no es error, pues dice: si tradición apócrifa no miente (fol. 29r.).

3. ...y cn boi, aunque rebelde, a quien el torno / forma elegante dio sin culto adorno... (I, 145-146).

Salcedo: No parece pequeño este descuido de don Luis. ¿Cómo le dio el torno forma elegante, y sin adorno culto? Elegante, ya se sabe q[ue] no solo en nuestro idioma. sino en otros, vale lo mismo que pulido, asseado, galano, gentil, hermoso. Adorno culto, quiere dezir lo mismo. Pues ¿ cómo se co[m]padece tener y no tener? ¿Ser pulido y no serlo?. Lo que quiso dezir don Luis fue que el torno, a pesar de su dureza, formó de vn tosco tronco de Box vna escudilla, pero sin la curiosidad que otros vasos de madera se suelen labrar... (fol. 42v.).

nota anónima: la más perfecta forma es la redonda.

4. leche... / ... / ... / gruesa le dan y fría / impenetrable casi a la cuchara... (I, 147151).

Silcedo: Era tan gruessa q[ue] apenas podría entrar en ella la cuchara, o por ventura sería por lo elado. Hypérbole galantíssimo. (fol. 43r.).

nota manuscrita: podría ser leche quaxada.

5. cuando el que vez sayal fue limpio acero. (I, 217)

Salcedo: Impropiedad me parece introduzir a vn rústico cabrero blasonando de auer sido soldado, pues qua[n]do desengañado se huuiese retirado de la milicia, le auia de fingir nuestro Poeta en más decente ocupación (fol. 56v.).

nota anónima: pequeña impropiedad es.

6. ...politico serrano, / de canas grave, habló de esta manera: (I. 364-365).

Salcedo: ¿Dónde pues estaua este viejo serrano? O ¿quándo llegó adonde estauan los demás? Si dize alguno que es el mesmo que le lleuó al peñasco de donde se descubría lo admirable de la campaña, no tiene fácil salida, porque aquí presupone que no le auía visto el anciano que habla, pues dizc que reconoció entonces el mar en en el vestido, $y$ que por esso hizo la exclamación que se sigue adelante. (fols. 76r. y 77 r.).

nota manuscrita: Este reparo es de poca consideración.

7. ...al que -ya deste o aquel mar- primero / surcó, labrador ficro (I, 369-370).

nota anónima: El mar en que estavan era el oceano, y el mar primero es el Mediterráneo.

(fol. 77).

8. ...sierpe de cristal... (I, 426).

nota anónima: mas ¿ por qué se llama sierpe de cristal? (fol. 100v.).

9. que en letras pocas lean muchos años (I, 943).

- Estas citas del anónimo remiten a las notas 12 y is. 
Salcedo: ...se lea[n] en pocas letras los muchos años que viuieron. Las palabras más solemnes con que querían significar que allí estaua sepultado alguno cra. Hic situs est wel hic jacet (fols. 178r. y a).

nota anónima: en letras pocas del algorismo se lean muchos años, yo entiendo que es el número de 100, que es quien tiene menos letras de todos, y es cdad muy crecida. 10. ...pie errante... (II, 166).

Salcedo: llámale errante, o por su atreuimiento, o por lo incierto de su viage (fol. 220r.). nota anónima: erro, erras significa también andar.

11. ...la más dulce - sino la menos clara-_ / sílaba... (II, 187-188).

nota anónima: no declara este Author quál sílaba sea esta y yo entiendo qlue] es la última palabra que cantó el Peregrino.

12. ...tantos Palemo a su Lícore bella - suspende,... (II, 587-588).

nota anónima: [subraya: Finge don Luis el sucesso deste peregrino en Italia, como ya diximos en la primera Soledad, y remite al lugal, fol. 19.] (fol. 271v.).

13. En sangre claro, y en persona Augusto,... (II, 809).

Salcedo: este Príncipe, que a lo que puedo conjeturar supone que era el Excel. Duque de Bejar... (fol. 295\%).

nota anónima: Duque de Béjar no me parece que sea, pues supone este comentador que este naufragio fue en Italia como afirma en la $1 .^{\text {a }}$ soledad fol. $19 !$ en la 2 : $^{\prime}$ fol. 271 yo entiendo que era e. Duque de Medina Sidonia y que este nanfragio fue en el Condado de Niebla, tierra suya.

Algunlas de estas apostillas son bastante peregrinas e. incluso. errores garrafales. Lo es de consideración la lectura que nos ofrece del pasaje señalado en la nota 7, entusiasmado como está en su descubrimiento, del que luego lablaremos, según el cual los poemas se localizan en el Condado de Niebla, es decir, en el Atlántico, y no en Italia y en el Mediterrineo, primero mar, como quiere Salcedo. También se equivoca en la 11. La 8 es una simple pregunta cicatera y facilona sobre algo que no la necesita. La 10 es de Pero Grullo. Las 3 y 9 son pintorescas. Las siete restantes presentan interés. En todas ellas se corrige a Salcedo. La observación que hace en la 4 es verosímil, puesto que, aunque dentro del sistema gongorino en nada nos extraña una hipérbole como la citada, en la que la leche, por ser buena, se hace tan espesa que es impenetrable a la cuchara, tenemos que tener en cuenta el verso que dice del viejo Alcemedón invención rara, por el cual podemos mantener la posición del anónimo. Son mís ciertos, sin duda alguna, sus criterios de verosimilitud que los de Salcedo en las notas 2,5 y 6 . El primer caso es típico del prosaísmo en que cae Góngora, deliberadamente. buscando una exactitud estéticn más que lógica. Góngora se convierte casi en grave historiador cuando a un mito añade la crítica: si lradici apócrifa no miente. Aunque el anotador anónimo creo que no entiende la belleza de este prosaísmo y lo toma, igual que Salcedo, por la tremenda, como si don Luis fuese un perseguidor de mitos y milagros de principios del 
siglo xviı. En la 5 coincide con el anotadór editado por Wilson. Los dos desconocidos llevan razón frente a Salcedo. Al menos dentro de la verosimilitud poética que parte del Renacimiento y en una obra en parte bucólica como son las Soledades. Más abierta es todavía su posición cuando asegura que no es reparo de consideración la aparición, más o menos súbita, del viejo. Por fin, las 1, 12 y 13, ligadas entre sí, plantean la cuestión del lugar donde se desarrolló el poema: en Italia, según Salcedo; en el Condado de Niebla, según el anónimo. Góngora no lo dice, ni lo sabe, seguramente Ell utiliza océano como mar. Pero si la respuesta no es exacta, la opinión de Salcedo tampoco. Lo mismo podríamos decir de la personalidad de ese noble cazador. ¿Pensaría Góngora, en la continuación del poema, aludir, como sospecha Salcedo, al Duque de Béjar, patrono de estos versos y al que presenta en la dedicatoria como cazador? Es ahí, en la caza, donde, lamentablemente, don Luis cortó sus Soledades.

Juan Manuel Rozas. 